\section{Susmita Bose appointed JMR associate editor for biomaterials}

mrs.org/jmr
Endowed Chair Professor in the School of Mechanical and Materials Engineering at Washington State University.

Bose received her $\mathrm{PhD}$ degree in physical-organic chemistry from Rutgers, The State University of New Jersey in 1998. Her interdisciplinary research interests lie at the interface of chemistry, biology, bioengineering, materials science, and engineering, focusing on different biomaterials and 3D printing of ceramic and composite materials for various applications, including drug delivery, bone-tissue engineering, and surface modification of bone implants.

Bose received the Presidential Early Career Award for Scientist and Engineers from the National Science Foundation and was named a Kavli Fellow by the National Academy of Sciences. In 2009, she received the Schwartzwalder-Professional Achievement in Ceramic Engineering

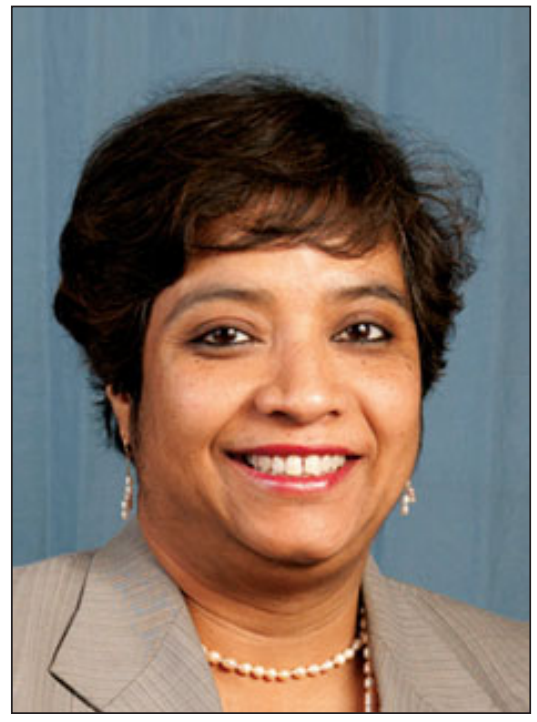

Award, the Richard M. Fulrath Award from The American Ceramic Society in 2014, and the International Society of Ceramics in Medicine Research Excellence Award in 2016. Bose is an editorial board member of several international journals and holds six US patents. She is a Fellow of the American Association for the Advancement of Science, the American Institute for Medical and Biological Engineering, and The American Ceramic Society. Bose is an editorial board member of several international journals and holds seven US patents. terials science in JMR," stated Messing Bose is the Herman and Brita Lindholm

\title{
Brosnan, LaVan, Paruch, Redwing, and Someya to chair 2018 MRS Fall Meeting
}

www.mrs.org/fall2018

$\mathrm{M}$ eeting chairs for the 2018 Materials Research Society (MRS) Fall Meeting are Kristen H. Brosnan (GE Global Research, USA), David LaVan (National Institute of Standards and Technology, USA), Patrycja Paruch (University of Geneva, Switzerland), Joan M. Redwing (The Pennsylvania State University, USA), and Takao Someya (The University of Tokyo, Japan). The Meeting will be held November 25-30, 2018, in Boston, Mass.

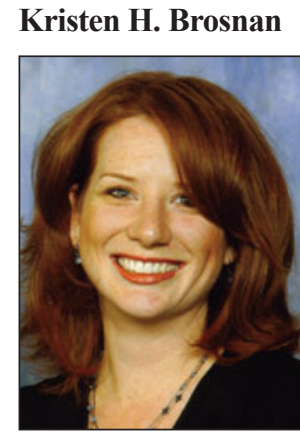

Kristen H. Brosnan is the manager of the Ceramics Laboratory at $\mathrm{GE}$ Global Research. She received her $\mathrm{BS}$ degree in materials science and engineering from Georgia Institute of Technology in 1999. She received her MS degree in 2002 and $\mathrm{PhD}$ degree in 2007, both in materials science and engineering at The Pennsylvania State University.

Brosnan has been with GE for 10 years, starting as a materials scientist at the Global Research Center studying microstructure-properties-performance relationships in ceramic thermal-spray coatings. Currently, her team in the Ceramics Laboratory is delivering key ceramic technology for GE Power and 